\title{
BMJ Open Association between de Quervain syndrome and herpes zoster: a population-based cohort study
}

\author{
Chao-Yu Hsu, ${ }^{1,2,3,4,5}$ Der-Shin Ke, ${ }^{1}$ Cheng-Li Lin, ${ }^{6,7}$ Chia-Hung Kao (1) 8,9,10,11
}

To cite: Hsu C-Y, Ke D-S, Lin C$\mathrm{L}$, et al. Association between de Quervain syndrome and herpes zoster: a populationbased cohort study. BMJ Open 2021;11:e046891. doi:10.1136/ bmjopen-2020-046891

- Prepublication history for this paper is available online To view these files, please visit the journal online (http://dx.doi org/10.1136/bmjopen-2020046891).

Received 12 November 2020 Accepted 26 November 2021
Check for updates

(C) Author(s) (or their employer(s)) 2021. Re-use permitted under CC BY-NC. No commercial re-use. See rights and permissions. Published by BMJ.

For numbered affiliations see end of article.

Correspondence to Dr Chia-Hung Kao; d10040@mail.cmuh.org.tw

\section{ABSTRACT}

Objective Both physical diseases such as infection and chronic pain and psychological disorders such as depression have been associated with herpes zoster (HZ) reactivation. However, the relationship between de Quervain syndrome (DQS), a painful tenosynovitis and $\mathrm{HZ}$ remains unclear. We investigated whether DQS increases the risk of $\mathrm{HZ}$ reactivation.

Design A retrospective population-based cohort study. Setting Taiwan.

Participants We used a subset of Taiwan's National Health Insurance Research Database, the Longitudinal Health Insurance Database which contains the registration files and original claims data of 1 million randomly selected individuals from the National Health Insurance programme. The case group in this study comprised patients newly diagnosed with DQS between 2000 and 2012. Individuals without DQS comprised the control group. Cases and controls were 1:1 matched by age, sex and index year (defined as the year of DQS diagnosis).

Results Approximately $55 \%$ of the participants were $\leq 49$ years. Most participants were women (77\%). The incidence rate of $\mathrm{HZ}$ in the DQS group was 8.39 per 1000 person years. After adjustments for age, sex and comorbidities, patients with DQS had a 1.30 times higher risk of $\mathrm{HZ}$ reactivation than the control group. Stratification analysis revealed taht $\mathrm{DQS}$ increases the $\mathrm{HZ}$ risk in individuals $\leq 64$ years, women, and patients without comorbidities. Conclusion DQS is associated with an increased risk of $\mathrm{HZ}$. Clinicians should be aware of this risk when dealing with patients with DQS, particularly in young adults.

\section{INTRODUCTION}

De Quervain syndrome (DQS), also termed tenosynovitis, is a painful inflammation of the tendons on the radial side of the wrist. ${ }^{1}$ The prevalence of DQS is higher in women (approximately $1.3 \%$ ) than in men $(0.5 \%){ }^{2}$ Typically, it affects individuals in their forties and fifties. ${ }^{3}$ Wolf $e t a l$ analysed a military database and revealed that the incidence of DQS in a young, active population was 2.8 and 0.6 per 1000 person years for women and men, respectively. They also reported that female sex was a risk factor for DQS. ${ }^{4}$ A single-dose steroid injection could alleviate symptoms in $82 \%$ of patients with DQS within 6 weeks. ${ }^{5}$
Strengths and limitations of this study

This population-based study was conducted using the National Health Insurance Research Database (NHIRD), which is a highly representative sample of the Taiwanese because it has a large sample size and thus the findings are highly generalisable.

- The patients were selected from the NHIRD based on diagnostic codes, which may have specialistassociated bias.

- Data on DQS and $\mathrm{HZ}$ severity are not available in the NHIRD and could therefore not be used in this study.

- Self-payment treatments for DQS or $\mathrm{HZ}$ are also not recorded in the NHIRD.

In Taiwan, the incidence of herpes zoster (HZ) increased from 5.04 cases per 1000 person years in 2004 to 5.65 in 2008. Moreover, HZ incidence increases with age, being 3.59 cases per 1000 person years in patients $\leq 49$ years, and 12.81 cases per 1000 person years in patients aged 65-74 years in $2008 .^{6}$ In Italy and Germany, the incidence rate of $\mathrm{HZ}$ in adults aged $\geq 50$ years was 6.46 and 6.7 per 1000 person years. ${ }^{78}$ The highest incidence rate was 9.4 per 1000 person years in German adults aged $\geq 80$ years. ${ }^{8}$ Recently, Tseng et al observed that the incidence rate of HZ was as high as 9.92 per 1000 person years in immunocompetent, unvaccinated adults aged $\geq 50$ years. ${ }^{9}$ Postherpetic neuralgia is a problematic complication of $\mathrm{HZ}$, it is found in $10 \%-15 \%$ of patients with $\mathrm{HZ}^{7}$ and the pain can last from months to years.

Stress, including physical stress in the form of diseases, is associated with the development of HZ. Infection, ${ }^{10} 11$ chronic pain-associated diseases (such as chronic interstitial cystitis, ${ }^{12}$ adhesive capsulitis of the shoulder, ${ }^{13}$ lateral epicondylitis, ${ }^{14}$ sciatica $^{15}$ and varicocele ${ }^{16}$ ) and psychological disorders (such as depres$\operatorname{sion}^{17}{ }^{18}$ ) have all been associated with $\mathrm{HZ}$ reactivation. DQS and the associated pain may be stressful for affected individuals. Furthermore, pain is highly correlated with 
depression. ${ }^{19}$ Thus, a correlation may exist between DQS and HZ. Here, we investigated whether DQS increases the risk of $\mathrm{HZ}$ reactivation.

\section{MATERIALS AND METHODS}

\section{Patient and public involvement}

The single-payer National Health Insurance (NHI) programme in Taiwan was initiated on 1 March 1995. Over $99 \%$ of Taiwan's population is now covered by the programme. The medical records of enrollees are registered in the National Health Insurance Research Database (NHIRD). In this study, we used the Longitudinal Health Insurance Database, a subset of the NHIRD, which contains data of 1 million randomly selected enrollees from the NHI programme. The identification information was encrypted before use for research. The disease codes were identified according to the International Classification of Diseases, Ninth Revision, Clinical Modification (ICD-9-CM).

\section{Study population}

The case group comprised patients newly diagnosed with DQS (ICD-9-CM code: 727.04) from 2000 to 2012, and the control group comprised patients without DQS. We excluded patients with a history of $\mathrm{HZ}$ reactivation and patients younger than 20 years. Cases and controls were 1:1 matched by age, sex and index year (defined as the year of DQS diagnosis). All study participants were followed up until they were diagnosed with $\mathrm{HZ}$ occurrence, were lost to follow-up, died or until 31 December 2013.

\section{Main outcome and comorbidities}

HZ occurrence (ICD-9-CM code: 053 ) was the primary outcome of the present study. We considered the presence of the following comorbidities as potential confounders: chronic kidney disease (CKD; ICD-9-CM code: 585, 586), obesity (ICD-9-CM code: 278), diabetes (ICD-9-CM code: 250), coronary artery disease (CAD; ICD-9-CM code: 410-414) and depression (ICD-9-CM code: 296.2, 296.3, 300.4 and 311$)$.

\section{Statistical analysis}

The baseline demographic characteristics and comorbidities of the case and control groups were compared using the $\chi^{2}$ test and t-test. We calculated the incidence rate as per 1000 person years. The Cox proportional hazards regression model was applied to estimate HRs after adjustment for the following variables as appropriate: age, sex and the comorbidities of CKD, diabetes, $\mathrm{CAD}$ and depression. Stratified analysis of age group, sex and comorbidities was also performed. We obtained the cumulative incidence of HZ by using the Kaplan-Meier method and examined intergroup differences using a log-rank test; $\mathrm{p} \leq 0.05$ was set as statistically significant.

\section{RESULTS}

This study recruited 8390 participants (4195 cases and 4195 controls). The mean follow-up time was $6.68( \pm 3.63)$
Table 1 Demographic characteristics and comorbidities in cohorts with and without de Quervain syndrome

\begin{tabular}{|c|c|c|c|}
\hline \multirow[b]{3}{*}{ Variable } & \multicolumn{2}{|c|}{ de Quervain syndrome } & \multirow[b]{3}{*}{$P$ value } \\
\hline & No & Yes & \\
\hline & $\mathrm{N}=4195$ & $\mathrm{~N}=4195$ & \\
\hline Age, year & & & 0.99 \\
\hline$\leq 49$ & $2299(54.8)$ & $2299(54.8)$ & \\
\hline $50-64$ & $1552(37.0)$ & $1552(37.0)$ & \\
\hline $65+$ & $344(8.20)$ & $344(8.20)$ & \\
\hline Mean $\pm \mathrm{SD}^{*}$ & $46.9 \pm 13.9$ & $46.8 \pm 13.5$ & \\
\hline Sex & & & 0.99 \\
\hline Female & $3229(77.0)$ & 3229 (77.0) & \\
\hline Male & $966(23.0)$ & $966(23.0)$ & \\
\hline \multicolumn{4}{|l|}{ Comorbidity } \\
\hline Diabetes & $222(5.29)$ & $209(4.98)$ & 0.52 \\
\hline CAD & $414(9.87)$ & $499(11.9)$ & 0.003 \\
\hline Depression & $227(5.41)$ & $281(6.70)$ & 0.01 \\
\hline Chronic kidney disease & $43(1.03)$ & $28(0.67)$ & 0.07 \\
\hline Obesity & $78(1.86)$ & $105(2.50)$ & 0.04 \\
\hline Cancer & $101(2.41)$ & $106(2.53)$ & 0.72 \\
\hline
\end{tabular}

Chi-Square Test

*T-Test

$C A D$, coronary artery disease.

years for the case group and $6.60( \pm 3.62)$ years for the control group. Table 1 compares the baseline characteristics between the two groups. Almost 55\% of the participants were younger than 49 years. Mean age for the two groups was approximately 47 years. Most participants were women $(77 \%)$. The distributions of CKD, diabetes and cancer were similar between the two groups. The percentages of patients with obesity, CAD and depression were higher in the DQS cohort than in the DQS-free cohort.

The incidence rate of $\mathrm{HZ}$ in the case group was 8.39 per 1000 person years. Cases were 1.30 times $(95 \%$ CI 1.16 to 1.47) more likely than the controls to have HZ (table 2). The adjusted HR of HZ occurrence in the subgroup aged 50-64 years was 2.65 (95\% CI 2.31 to 3.04) and that in the subgroup aged $\geq 65$ years was 2.79 (95\% CI 2.27 to 3.43 ), with patients $\leq 49$ years old considered the reference group. Patients with CKD, diabetes, CAD and depression also had significantly higher risks of developing HZ.

Stratified analysis (table 3 ) revealed that DQS increased $\mathrm{HZ}$ risk in individuals $\leq 64$ years, women and patients without comorbidities. The cumulative incidence curve for the patients with DQS was higher than that for the controls. The difference between the two curves was significant (log-rank test: $\mathrm{p}=0.007$; figure 1 ).

\section{DISCUSSION}

This is the first retrospective population-based study to demonstrate the association between DQS and HZ 
Table 2 The incidence and risk factors for herpes zoster

\begin{tabular}{|c|c|c|c|c|c|}
\hline Variable & Event & PY & Rate $^{\#}$ & Crude HR (95\% Cl) & Adjusted HR (95\% Cl) \\
\hline \multicolumn{6}{|c|}{ de Quervain } \\
\hline No & 154 & 24442 & 6.30 & 1.00 & 1.00 \\
\hline \multicolumn{6}{|l|}{ Age, year } \\
\hline$\leq 49$ & 113 & 28427 & 3.98 & 1.00 & 1.00 \\
\hline $65+$ & 48 & 3421 & 14.0 & $3.53(2.91 \text { to } 4.28)^{\star \star *}$ & $2.79(2.27 \text { to } 3.43)^{\star \star \star}$ \\
\hline \multicolumn{6}{|l|}{ Sex } \\
\hline Female & 294 & 37761 & 7.79 & $1.33(1.13 \text { to } 1.55)^{\star \star \star}$ & 1.07 (0.92 to 1.25$)$ \\
\hline Male & 66 & 11238 & 5.87 & 1.00 & 1.00 \\
\hline \multicolumn{6}{|c|}{ Comorbidity } \\
\hline Yes & 36 & 2325 & 15.5 & $2.23(1.83 \text { to } 2.72)^{\star \star \star}$ & $1.33(1.08 \text { to } 1.64)^{\star * \star}$ \\
\hline \multicolumn{6}{|l|}{ CAD } \\
\hline No & 285 & 44009 & 6.48 & 1.00 & 1.00 \\
\hline Yes & 75 & 4991 & 15.0 & $2.32(2.00 \text { to } 2.69)^{\star \star *}$ & $1.42(1.21 \text { to } 1.66)^{\star \star *}$ \\
\hline \multicolumn{6}{|c|}{ Depression } \\
\hline No & 330 & 46482 & 7.10 & 1.00 & 1.00 \\
\hline Yes & 30 & 2518 & 11.9 & $1.68(1.35 \text { to } 2.09)^{\star \star \star}$ & $1.35(1.09 \text { to } 1.68)^{\star \star \star}$ \\
\hline \multicolumn{6}{|c|}{$\begin{array}{l}\text { Chronic kidney } \\
\text { disease }\end{array}$} \\
\hline No & 353 & 48054 & 7.35 & 1.00 & 1.00 \\
\hline Yes & 7 & 945 & 7.41 & 1.01 (0.65 to 1.56$)$ & \\
\hline
\end{tabular}

Rate $^{\#}$, incidence rate, per 1000 person years; Crude $\mathrm{HR}^{*}$, relative $\mathrm{HR}$; Adjusted $\mathrm{HR}^{\dagger}$ : multivariable analysis including age, sex, and comorbidities of diabetes, CAD, depression, and chronic kidney disease;

${ }^{*} \mathrm{p}<0.05,{ }^{* \star} \mathrm{p}<0.01,{ }^{* \star *} \mathrm{p}<0.001$

reactivation. We observed that patients with DQS had a higher risk of $\mathrm{HZ}$ than those without DQS. After adjustments for age, sex and comorbidities, patients with DQS were found to be 1.3 times more likely to develop HZ.

Petit Le Manac'h et al found the prevalence of DQS among the working population to be $1.2 \%$, with the prevalence for women and men being $2.1 \%$ and $0.6 \%$, respectively. They also reported that the most significant factors related to work were twisting or driving screws. ${ }^{20}$ These tasks involve bending and twisting of the wrist. Because DQS is more common in women, oestrogen involvement in the pathogenesis of DQS should be considered. Shen $e t$ $a l$ concluded that patients with relatively high oestrogen receptor (ER) $\beta$ expression exhibited more severe DQS and that ER- $\beta$ may be a useful target for DQS treatment. ${ }^{21}$ However, only a limited number of patients were enrolled in that study. In our cohort, most patients with DQS were women, consistent with previous studies.

Our study found that patients with CAD or CKD had a higher risk of HZ. In 1989, the Framingham Heart Study did not identify a strong association between herpes occurrence and CAD incidence among elderly people..$^{223}$ Subsequently, Esteban-Hernández et al reported a high association between herpes and ischaemic heart disease (OR: 4.5) after adjustment for comorbidities, without hypercholesterolaemia. ${ }^{24} \mathrm{~A}$ meta-analysis study assessed the relationship between cardiac risk and $\mathrm{HZ}$ development 
Table 3 Incidence of herpes zoster by age, sex and comorbidity and Cox model measured HR for patients with de Quervain syndrome compared those without de Quervain syndrome

\begin{tabular}{|c|c|c|c|c|c|c|c|c|}
\hline \multirow[b]{3}{*}{ Variables } & \multicolumn{6}{|c|}{ de Quervain } & \multirow{3}{*}{$\begin{array}{l}\text { Crude HR } \\
(95 \% \mathrm{Cl})\end{array}$} & \multirow{3}{*}{$\begin{array}{l}\text { Adjusted HR }{ }^{\&} \\
(95 \% \mathrm{Cl})\end{array}$} \\
\hline & \multicolumn{3}{|l|}{ No } & \multicolumn{3}{|l|}{ Yes } & & \\
\hline & Event & PY & Rate $^{\#}$ & Event & PY & Rate $^{\#}$ & & \\
\hline$\leq 49$ & 43 & 14211 & 3.03 & 70 & 14216 & 4.92 & $1.63(1.36 \text { to } 1.94)^{\star \star \star}$ & $1.57(1.32 \text { to } 1.87)^{\star \star \star}$ \\
\hline $50-64$ & 88 & 88 & 10.2 & 111 & 8551 & 13.0 & $1.27(1.05 \text { to } 1.53)^{\star \star \star}$ & $1.25(1.03 \text { to } 1.51)^{\star \star *}$ \\
\hline \multicolumn{9}{|l|}{ Sex } \\
\hline Female & 120 & 18899 & 6.35 & 174 & 18863 & 9.22 & $1.45(1.27 \text { to } 1.67)^{\star \star \star}$ & $1.43(1.25 \text { to } 1.64)^{\star \star \star}$ \\
\hline Male & 34 & 5543 & 6.13 & 32 & 5695 & 5.62 & 0.92 (0.70 to 1.19$)$ & $0.87(0.68$ to 1.13$)$ \\
\hline \multicolumn{9}{|c|}{ Comorbidity } \\
\hline No & 105 & 20150 & 5.21 & 137 & 19320 & 7.09 & $1.36(1.18 \text { to } 1.56)^{\star \star \star}$ & $1.36(1.19 \text { to } 1.56)^{\star \star \star}$ \\
\hline
\end{tabular}

Rate $^{\#}$, incidence rate, per 1,000 person-years; Crude $\mathrm{HR}^{*}$, relative hazard ratio; Adjusted $\mathrm{HR}^{\dagger}$ : multivariable analysis including age, sex, and comorbidities of diabetes, CAD, depression, and chronic kidney disease.

$\S$ Individuals with any comorbidity of diabetes, CAD, depression, and chronic kidney disease, obesity, and cancer were classified into the comorbidity group.

${ }^{*} \mathrm{p}<0.05,{ }^{\star *} \mathrm{p}<0.01,{ }^{* \star *} \mathrm{p}<0.001$.

and found that cardiac events were significantly increased after $\mathrm{HZ}$ onset; the ORs were 1.31 at 3 months, 1.19 up to 1 year and 1.12 more than 1 year after HZ occurrence. ${ }^{25}$ Increased cardiovascular risks after HZ development have been identified, but HZ risk following cardiovascular events remains unclear. However, in the present study, patients with CAD had a 1.42-fold increased risk of HZ.

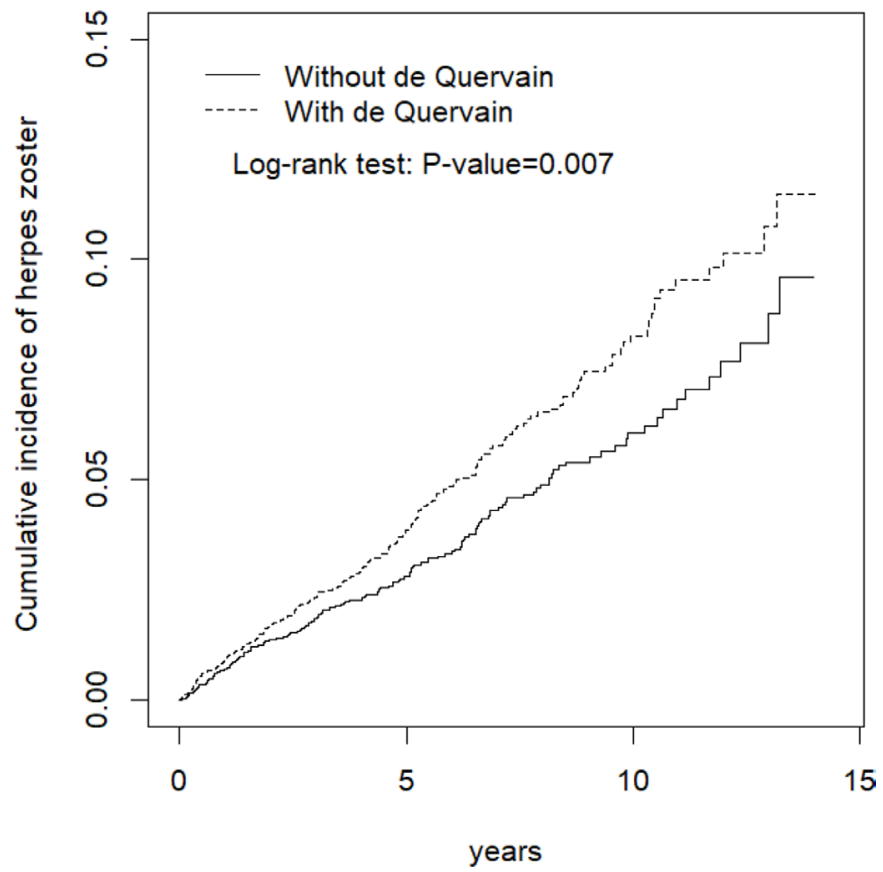

Figure 1 Cummulative incidence comparison of herpes zoster for patients with (dashed line) or without (solid line) de Quervain syndrome.
Several researchers have attempted to identify HZ risk among patients with CKD. Sato et al found that the incidence of $\mathrm{HZ}$ was only 8.2 per 1000 person years in patients with stage 1,2 or $3 \mathrm{CKD}$, but increased to as high as 84.8 per 1000 person years in patients under haemodialysis or peritoneal dialysis. ${ }^{26}$ Lin et al analysed HZ risk based on sustained kidney damage and therapy received, reporting that the HR of HZ occurrence was 8.46 for the renal transplantation group, 3.61 for the peritoneal dialysis group, 1.35 for the haemodialysis group and 1.21 for the CKD group compared with the control group. ${ }^{27}$

Mortality is high after $\mathrm{HZ}$ reactivation in patients with end-stage renal disease (ESRD). Ahn et al reported that half of patients with ESRD died within 2years following HZ (mean time to death: 8.1 months). They also found that mortality increased as age and Charlson Comorbidity Index Score increased. ${ }^{28}$ Comparing the incidence of $\mathrm{HZ}$ occurrence in ESRD patients with and without $\mathrm{HZ}$ vaccination, Tseng et al reported that the incidence of $\mathrm{HZ}$ was 11.7 per 1000 person years for the vaccinated group and 22.3 per 1000 person years for the unvaccinated group; thus, $\mathrm{HZ}$ vaccination reduced the risk by half. The authors concluded that $\mathrm{HZ}$ vaccination may provide a better protection soon after the initiation of dialysis. ${ }^{29} \mathrm{In}$ our study, patients with CKD were 1.34 times more likely to develop HZ.

$\mathrm{CAD}$ and $\mathrm{CKD}$ are considered risk factors for $\mathrm{HZ}$ reactivation. Our findings demonstrated that among participants with any comorbidities, individuals with DQS had a slightly higher risk of $\mathrm{HZ}$ than those without DQS. However, among patients without any comorbidities, HZ risk in patients with DQS was 1.36 times higher than in 
those without DQS (table 3). This means that DQS must be a serious stressor for affected persons. In general, HZ incidence increases with age. Our results revealed that the risk of HZ among DQS patients was the highest in the age group of $<50$ years (table 3 ). Therefore, in our view, the disease burden of DQS should not be ignored, particularly among younger adults.

This was a population-based study conducted using NHIRD records. The NHIRD contains a highly representative sample of the Taiwanese population because it has a large sample size and the findings are highly generalisable. However, this study has several limitations. First, the data were selected from the NHIRD records based on diagnostic codes. The diagnosis of DQS and HZ might be made by neurologists, orthopedists, general practitioners or dermatologists who employ differing methods or criteria; thus, bias may exist related to the diagnostic codes of medical specialists. However, the NHI Administration audits the claims and enforces a punishment system. All claims are sent to the NHI Administration and checked by reimbursement experts. Therefore, the diagnostic codes are highly reliable. Second, NHIRD does not have data on DQS and HZ severity. The severity of diseases may influence treatment decision-making and affect prognosis. Third, self-payment treatments for DQS or HZ are not recorded in the NHIRD. Some patients might have used traditional Chinese medicine methods such as acupuncture or medicinal herb, to relieve pain at their own expense, resulting in an underestimation of the prevalence of DQS or HZ. Fourth, self-paid HZ vaccines might not be recorded in the NHIRD. The HZ vaccine has been available in Taiwan since 2013, but it is expensive and not covered by the NHI. Therefore, HZ vaccination is not common in Taiwan. This study followed enrollees until the end of 2013, and hence, the influence of the HZ vaccine can be ignored. Regardless of the limitations, our study reflects real-world circumstances with numerous samples and highly generalisability. Our data strongly indicate that patients with DQS have a higher HZ risk than those without. These findings may serve as reference for future research.

\section{CONCLUSION}

DQS is associated with an increased risk of HZ. Clinicians should be aware of this risk when dealing with patients with DQS, particularly in young adults.

\footnotetext{
Author affiliations

${ }^{1}$ Department of Medical Education, Ditmanson Medical Foundation, Chia-Yi Christian Hospital, Chia-Yi, Taiwan

${ }^{2}$ Department of Optometry / Medical Imaging and Radiological Sciences, Central Taiwan University of Science and Technology, Taichung, Taiwan

${ }^{3}$ Center for General Education, National Taichung University of Science and Technology, Taichung, Taiwan

${ }^{4}$ Department of General Education, National Chin-Yi University of Technology, Taichung, Taiwan

${ }^{5}$ Rural Generalist Program Japan, GENEPRO, Japan

${ }^{6}$ Management Office for Health Data, China Medical University Hospital, Taichung, Taiwan
}

${ }^{7}$ College of Medicine, China Medical University, Taichung, Taiwan

${ }^{8}$ Graduate Institute of Biomedical Sciences and School of Medicine, College of Medicine, China Medical University, Taichung, Taiwan

${ }^{9}$ Department of Nuclear Medicine and PET Center, China Medical University Hospital, Taichung, Taiwan

${ }^{10}$ Department of Bioinformatics and Medical Engineering, Asia University, Taichung, Taiwan

${ }^{11}$ Center of Augmented Intelligence in Healthcare, China Medical University Hospital, Taichung, Taiwan

Contributors Conceptualisation: C-YH, C-HK. Methodology, software, investigation, resources: C-LL, C-HK. Validation, formal analysis, data curation, writing (original draft preparation), writing (review and editing) and visualisation: all authors. Supervision, project administration, funding acquisition: C-HK. All authors approved and agreed to submit the manuscript. C-HK is responsible for this study.

Funding This work was supported by grants from the Taiwan Ministry of Health and Welfare Clinical Trial Center (MOHW110-TDU-B-212-124004); China Medical University Hospital (DMR-110-089, DMR-110-222, DMR-111-090, DMR-111-091); MOST Clinical Trial Consortium for Stroke (MOST 110-2321-B-039-003); TsengLien Lin Foundation, Taichung, Taiwan. The funders had no role in the study design, data collection and analysis, decision to publish, or preparation of the manuscript. No additional external funding was received for this study.

\section{Competing interests None declared.}

Patient and public involvement Patients and/or the public were involved in the design, or conduct, or reporting, or dissemination plans of this research. Refer to the Methods section for further details.

Patient consent for publication Not applicable.

Ethics approval The NHIRD encrypts patients' personal information to protect privacy and provides researchers with anonymous identification numbers associated with relevant claims information, including sex, date of birth, medical services received, and prescriptions. Therefore, patient consent is not required to access the NHIRD. This study was approved by the Institutional Review Board (IRB) of China Medical University (CMUH104-REC2-115-CR4); the IRB also waived the consent requirement.

Provenance and peer review Not commissioned; externally peer reviewed.

Data availability statement Data may be obtained from a third party and are not publicly available. The NHIRD is maintained by the Taiwan Ministry of Health and Welfare (MOHW). The application to access the data for this study was approved by the MOHW. Any researcher interested in the data from the NHIRD can submit an application form to the MOHW or contact the staff of the MOHW (Email: stcarolwu@ mohw.gov.tw) for assistance.

Open access This is an open access article distributed in accordance with the Creative Commons Attribution Non Commercial (CC BY-NC 4.0) license, which permits others to distribute, remix, adapt, build upon this work non-commercially, and license their derivative works on different terms, provided the original work is properly cited, appropriate credit is given, any changes made indicated, and the use is non-commercial. See: http://creativecommons.org/licenses/by-nc/4.0/.

ORCID iD

Chia-Hung Kao http://orcid.org/0000-0002-6368-3676

\section{REFERENCES}

1 Cooper C, Hunter's PK, Occupations Dof. Chapter 57: Repeated movements and repeated trauma affecting the musculoskeletal system. In: Edited by Baxter PJ, Aw Tc, Cockcroft a, et al. Tenth Edition. Hodder Arnold, 2010.

2 Walker-Bone K, Palmer KT, Reading I, et al. Prevalence and impact of musculoskeletal disorders of the upper limb in the general population. Arthritis Care Res 2004;51:642-51.

3 Satteson E, Tannan SC, De Quervain Tenosynovitis. StatPearls [Internet]. Treasure Island (FL): StatPearls Publishing 2019. -.

4 Wolf JM, Sturdivant RX, Owens BD. Incidence of de Quervain's Tenosynovitis in a Young, Active Population. J Hand Surg Am 2009;34:112-5.

5 Earp BE, Han CH, Floyd WE, et al. de Quervain Tendinopathy: Survivorship and Prognostic Indicators of Recurrence Following A Single Corticosteroid Injection. J Hand Surg Am 2015;40:1161-5. 
6 WH L, Lin CW, Wang CY. Cet al. epidemiology and long-term disease burden of herpes zoster and postherpetic neuralgia in Taiwan: a population-based, propensity score-matched cohort study. BMC Public Health 2018;18:369.

7 Salvetti A, Ferrari V, Garofalo R, et al. Incidence of herpes zoster and postherpetic neuralgia in Italian adults aged $\geq 50$ years: A prospective study. Preventive Medicine Reports 2019;14:100882.

8 Schmidt-Ott R, Schutter U, Simon J, et al. Incidence and costs of herpes zoster and postherpetic neuralgia in German adults aged $\geq 50$ years: a prospective study. Journal of Infection 2018;76:475-82.

9 Tseng HF, Bruxvoort K, Ackerson B, et al. The epidemiology of herpes zoster in immunocompetent, unvaccinated adults $\geq 50$ years old: incidence, complications, hospitalization, mortality, and recurrence. J Infect Dis 2020;222:798-806.

10 Hsu C-Y, Lin C-L, Kao C-H. Balanitis is a risk factor for herpes zoster Eur J Clin Microbiol Infect Dis 2015;34:985-90.

11 Hsu C-Y, Wang Y-C, Kao C-H. Dyshidrosis is a risk factor for herpes zoster. J Eur Acad Dermatol Venereol 2015;29:2177-83.

12 Hsu C-Y, Lin C-L, Kao C-H. Association between chronic interstitial cystitis and herpes zoster. Int J Environ Res Public Health 2020;17:2228.

13 Hsu C-Y, Ke D-S, Lin C-L, et al. Risk of herpes zoster in patients with adhesive Capsulitis of the shoulder. Int $J$ Environ Res Public Health 2020;17:3592.

14 Hsu C-Y, Ke D-S, Lin C-L, et al. Association between lateral epicondylitis and the risk of herpes zoster development. Postgrad Med 2021;133:96-101.

15 DS K, Hsu CY, Lin CL. Herpes zoster in patients with sciatica. BMC Musculoskelet Disord 2020;21:813.

16 Hsu C-Y, Ke D-S, Lin C-L, et al. Risk of herpes zoster infection in men with varicocele. Postgrad Med 2021;133:599-603.

17 Choi HG, Kim EJ, Lee YK. The risk of herpes zoster virus infection in patients with depression: a longitudinal follow-up study using a national sample cohort. Medicine 2019;98:e17430.
18 Liao C-H, Chang C-S, Muo C-H, et al. High prevalence of herpes zoster in patients with depression. J Clin Psychiatry 2015;76:e1099-104.

19 IsHak WW, Wen RY, Naghdechi L, et al. Pain and depression: a systematic review. Harv Rev Psychiatry 2018;26:352-63.

20 Petit Le Manac'h A, Roquelaure Y, Ha C, et al. Risk factors for de Quervain's disease in a French working population. Scand J Work Environ Health 2011;37:394-401.

21 Shen P-C, Wang P-H, Wu P-T, et al. The estrogen receptor- $\beta$ expression in de Quervain's disease. Int J Mol Sci 2015;16:26452-62.

22 Havlik RJ, Blackwelder WC, Kaslow R, et al. Unlikely association between clinically apparent herpesvirus infection and coronary incidence at older ages. The Framingham heart study. Arteriosclerosis 1989:9:877-80.

23 Tsai K-H, Lee N-H, Chen G-Y, et al. Dung-shen (Codonopsis pilosula) attenuated the cardiac-impaired insulin-like growth factor II receptor pathway on myocardial cells. Food Chem 2013;138:1856-67.

24 Esteban-Hernández J, San Román Montero J, Gil R. Association between herpetic burden and chronic ischemic heart disease: matched case-control study. Med Clin 2011;137:157-60.

25 Erskine N, Tran H, Levin L, et al. A systematic review and metaanalysis on herpes zoster and the risk of cardiac and cerebrovascular events. PLoS One 2017;12:e0181565.

26 Sato T, Inoue T, Endo K. End-Stage renal disease (ESRD) contributes to the increasing prevalence of herpes zoster. NDT Plus 2009;2:263-4.

27 Lin S-Y, Liu J-H, Lin C-L, et al. A comparison of herpes zoster incidence across the spectrum of chronic kidney disease, dialysis and transplantation. Am J Nephrol 2012;36:27-33.

28 Ahn JH, Waller JL, Baer SL, et al. Mortality risk after herpes zoster infection in end-stage renal disease patients. Clin Kidney $J$ 2019;12:101-5

29 Tseng HF, Luo Y, Shi J. Effectiveness of herpes zoster vaccine in patients 60 years and older with end-stage renal disease. Clin Infect Dis 2016;62:462-7. 